\title{
ben Functions with Scamp during Synaptic Transmission and Long-Term Memory Formation in Drosophila
}

\author{
Hong Zhao, ${ }^{1}$ Xingguo Zheng, ${ }^{1}$ Xiaojing Yuan, ${ }^{1}$ Lei Wang, ${ }^{1}$ Xin Wang, ${ }^{2}$ Yi Zhong, ${ }^{1,2,3}$ Zuoping Xie, ${ }^{1}$ and Tim Tully ${ }^{3,4}$ \\ ${ }^{1}$ State Key Laboratory of Biomembrane and Membrane Biotechnology, Department of Biological Sciences and Biotechnology, Tsinghua University, Beijing, \\ China 100084, ${ }^{2}$ JoeKai Inc., Beijing, China 100084, ${ }^{3}$ Cold Spring Harbor Laboratory, Cold Spring Harbor, New York 11724, and ${ }^{4}$ Dart Neuroscience LLC, San \\ Diego, California 92121
}

Genetic screens for Drosophila mutants defective in pavlovian olfactory memory have provided unique insight into the molecular basis of memory storage. Occasionally, these singular genetic lesions have been assembled into meaningful molecular pathways and neural circuitries. For the most part, however, these genes and their expression patterns in the CNS remain fragmented, demanding new clues from continued mutant screens. From a behavioral screen for long-term memory (LTM) mutants, we have identified ben (CG32594), which encodes a novel protein. Mutations of ben specifically disrupt LTM, leaving earlier memory phases intact. The role of ben appears physiological rather than developmental, because acutely induced expression of a ben ${ }^{+}$transgene in adults rescues the mutant's LTM defect. More interestingly, induced expression of ben ${ }^{+}$specifically in mushroom bodies (MBs), but not in the ellipsoid body of the central complex, is sufficient to rescue the mutant LTM defect. This suggests a role for ben in the MB during olfactory memory formation. We also provide evidence that BEN interacts genetically in both synaptic transmission and LTM formation with SCAMP, a synaptic protein known to be involved in vesicle recycling.

Key words: olfactory learning; synaptic transmission mutants; larval neuromuscular junction; mutant; learning and memory; neurotransmission

\section{Introduction}

Like other biological processes, complex behaviors (i.e., learning and memory) are shaped by selective pressure and are remarkably conserved across animal phyla. Such a genetic perspective provides the conceptual motivation to use "simple" model systems initially to discover specific genes involved in a given behavioral phenomenon and then to manipulate each gene's expression or function, thereby unraveling the relevant molecular and neuronal mechanisms. Olfactory memory in Drosophila melanogaster is a well established model system to study the genetic and neuronal architecture of associative learning. Of particular relevance, many genes identified from this model system have mammalian homologs with similar functions (Margulies et al., 2005), or, conversely, genes first discovered to be involved in mammalian plasticity also appear to be involved in associative learning in the fly (Xia et al., 2005; Wu et al., 2007, 2008; Bolduc et al., 2008). Therefore, lessons we learn from the neurogenetics of olfactory memory in

Received Aug. 20, 2008; revised Nov. 18, 2008; accepted Nov. 20, 2008

This work was supported by the National Basic Research Program of China (973 \#2005CB522503) to Z.X., by the National Basic Research Project (973 \#2006CB500800), the Tsinghua-Yue-Yuen Medical Sciences Fund to Y.Z., and by Dart Neuroscience LLC to T.T. We are grateful to the Bloomington Stock Center (Indiana University, Bloomington, IN) for providing stocks EY08069 and EP1593, to the Kyoto Stock Center (Kyoto Institute of Technology, Kyoto, Japan) for providing 4013, and to Berkeley Drosophila Genome Project for providing plasmid SD04373.

Correspondence should be addressed to either of the following: Dr. Tim Tully, Dart Neuroscience LLC, 7473 Lusk Boulevard, San Diego, CA 92075, E-mail: ttully@dartneuroscience.com; or Dr. Zuoping Xie, Department of Biological Sciences and Technology, Tsinghua University, Beijing, China 100084, E-mail: zuoping@tsinghua.edu.cn.

DOI:10.1523/JNEUROSCI.5036-07.2009

Copyright $\odot 2009$ Society for Neuroscience $\quad$ 0270-6474/09/290414-11\$15.00/0 flies should be relevant to our understanding of human cognition.

Past work on pavlovian olfactory memory in Drosophila has begun to elucidate the underlying molecules and circuits (Margulies et al., 2005; Keene and Waddell, 2007). To date, two observations are apparent. First, behavioral plasticity depends on a large fraction of the neuron's proteome (Ashraf et al., 2006). A biological pathway from synaptic dopamine and/or glutamatergic transmission through gene transcription to local protein translation is emerging as a central mechanism of long-term memory (LTM) formation (Petersen et al., 1997; Dubnau et al., 2003; Schwaerzel et al., 2003; Ge et al., 2004; Presente et al., 2004; Kim et al., 2007; Wu et al., 2007). More complete connections among genes in this network remain to be discovered, however. Second, distinct neuroanatomical structures underlie olfactory memory formation, including the antennal lobe $(\mathrm{AL})$, the mushroom body $(\mathrm{MB})$, and the ellipsoid body (EB) (Heisenberg et al., 1985; Connolly et al., 1996; Zars et al., 2000; Pascual and Preat, 2001; Akalal et al., 2006; Krashes et al., 2007; Lu et al., 2007; Wu et al., 2007). Moreover, imaging studies have revealed neural activities that potentially underlie this behavioral plasticity. Olfactory learning generates (1) one short-lived "memory trace" in the AL (Yu et al., 2004); (2) two additional, more persistent traces in dopaminergic or in dorsal paired medial neurons, both of which innervate MB neurons (Waddell et al., 2000; Riemensperger et al., 2005; Yu et al., 2005); (3) a fourth trace in the $\mathrm{MB} \alpha^{\prime}$ lobe, which is associated with short- to middle-term 
memory (Wang et al., 2008); and (4) a fifth trace, specific to axons of the MB $\alpha$ lobe, only after LTM formation (Yu et al., 2006). Additional anatomies and neural activities involved in memory storage or retrieval have not yet been discerned.

To expand our knowledge of genetic pathways and neural circuits, we conducted a behavioral screen for mutants defective in LTM after pavlovian olfactory learning (Lu et al., 2007; Qian et al., 2007) and identified the ben gene (CG32594), which encodes a novel protein. Although BEN is expressed throughout the brain, induced expression of a ben ${ }^{+}$transgene in MB is sufficient to rescue the mutant's LTM defect. The ben mutant also is defective in synaptic transmission at the larval neuromuscular junction (NMJ). Perusal of a protein interaction database suggested that BEN interacts with SCAMP, a protein involved in vesicle recycling. Scamp mutants also show defects in synaptic transmission (Fernandez-Chacon and Sudhof, 2000; Lloyd et al., 2000). We confirmed a functional interaction between BEN and SCAMP by showing defects for both LTM formation in adults and synaptic transmission at the larval NMJ in flies heterozygous for mutations in both genes.

\section{Materials and Methods}

Fly stocks. Transposon mutagenesis was performed as described in previous work (Lu et al., 2007; Qian et al., 2007). A PlacW autosomal mutator in a $\mathrm{CyO}$ balancer chromosome was used to generate $\mathrm{X}$-linked transposant strains. Two thousand twenty-one adult-viable homozygous strains were screened for defective $24 \mathrm{~h}$ memory after spaced training using a pavlovian olfactory task (Tully et al., 1994). After outcrossing to $w^{1118}$ (isoCJ1) for at least five generations to equilibrate genetic backgrounds and to remove most second-site mutations and after blind and balanced retesting, 11 candidate mutants were discovered with reliable $24 \mathrm{~h}$ memory defects. Based on molecular, genetic and behavioral characterizations of mutant strain 20816039 presented herein, we renamed the novel gene, CG32594, ben ("ben" means "stupid" in Mandarin) and the original mutant strain ben $^{P 1}$. The strain $\mathrm{w}\left[{ }^{*}\right] \mathrm{P}\{$ GawB $\} N P 4013 /$ FM7c was obtained from Kyoto Stock Center (Kyoto Institute of Technology, Kyoto, Japan). The strains $y^{1} w^{67 c 23 P}\left\{\right.$ EPgy2\} hiw ${ }^{\text {EY08069 }}$ (Bellen et al., 2004) and EP1593 (Lloyd et al., 2000) were obtained from Bloomington Stock Center (Indiana University, Bloomington, IN). The $w^{*}$;noc $c^{S c o}$ / CyO;P $\left\{\right.$ tubP-GAL80 $\left.0^{\text {ts }}\right\} 7 \quad\left(7018-G A L 80^{\text {ts }}\right), \quad w^{*} ; P\left\{t u b P-G A L 80^{t s}\right\} 20$; TM2/TM6B, $\mathrm{Tb}^{1}$ (7019-GAL80 ${ }^{\text {ts }}$ ) (McGuire et al., 2003), P26 (hsGAL4), 247-Gal4 (MB247), c739-Gal4 (c739), and Feb170-Gal4 (Feb170) drivers were extant stocks in our laboratory. All these strains were outcrossed with $w^{1118}$ (isoCJ1) flies for at least five generations to equilibrate genetic backgrounds. hiw $w^{N D 8}$ and hiw ${ }^{N D 9}$ were gifts from the laboratory of Dr. A. DiAntonio (Washington University School of Medicine, St. Louis, MO) and were crossed for five generations with FM7a balancer flies, which themselves had been outcrossed with $w^{1118}$ (isoCJ1). All the flies, if not mentioned specifically, were reared at $25^{\circ} \mathrm{C}$ and $60 \%$ relative humidity with a $14 / 10 \mathrm{~h}$ light/dark cycle. The $w^{1118}$ (isoCJ1), a Canton-S strain isogenic for the $\mathrm{X}$, second and third chromosomes (Yin et al., 1994), served as a "wild-type" control in all our experiments. Various genetic crosses generated the genotypes tested. Virgin ben ${ }^{P 1}$ homozygotes were crossed with ben ${ }^{E Y 08069}$ males or hiw ${ }^{N D 8}$ and hiw ${ }^{N D 9}$ males for the genetic complementation experiments. Virgin $b e n^{P 1}$; hs-Gal4 homozygotes were crossed with UAS$b e n^{+4-8}$ males for transgenic rescue. Virgin $b e n^{P 1}$; UAS-ben ${ }^{+4-8}$ homozygotes were crossed with Gal80 ${ }^{\text {ts }} ; 247$, c739 or Feb170 males for spatiotemporal rescue experiments. For experiments using the $\mathrm{X}$-linked Feb170 driver, ben ${ }^{P 1}$,Feb170 flies were bred first by crossing $b e n^{P 1}$ virgins with Feb170 males. Virgin $\mathrm{F}_{1}$ females $\left(b e n^{P 1},+1\right.$ + ,Feb170) then were crossed with FM7a males, and the miniwhitecarrying progeny females with darker eye color (presumably $b e n^{P 1}$,Feb170 recombinants) were crossed singly to FM7a males to generate a pure-breeding stock. The putative $b_{e n}{ }^{P 1}, F e b 170$ stock was confirmed by (1) detecting the $b e n^{P 1}$ genomic insertion with PCR and (2) demonstrating the presence of Feb170 by crossing the flies to UAS-green fluorescent protein. Virgin ben ${ }^{P 1}$ or ben ${ }^{E Y 08069}$ homozygotes were crossed with Scamp ${ }^{E P 1593}$ males for the epistasis experiments. Virgin Scamp ${ }^{E P 1593}$; hs-Gal4 homozygotes were crossed with $b e n^{P 1}$;UAS-ben ${ }^{+4-8}$ for the epistatic rescue experiment.

Plasmid rescue of the ben ${ }^{P 1}$ PlacW transposon insertion. Genomic DNA was isolated from homozygous $b e n^{P 1}$ mutants, digested to completion with EcoRl (NEB), and "plasmid rescued" as described previously (Dubnau et al., 2003). DNA sequence was obtained by automated sequencing (Applied Biosystems) with a primer directed against the $3^{\prime}$ long terminal repeat (LTR) of PlacW (5'-CGCCGACAAGCTTTGCGTACTCGC-3'). A blast of genomic DNA flanking the $3^{\prime}$ LTR identified the genomic insertion site of the PlacW transposon.

Generation of UAS-ben+ transgenic flies. The expected full-length $b^{+}{ }^{+}$cDNA was amplified by Pfu-polymerase (Stratagene) from cDNA clone SD04373 (DGRC) and sequenced to confirm its correctness. NotI restriction sites were added to both ends of the PCR product, which then was subcloned into a pUAST germ-line transformation vector. Transformation was performed by BestGene. Ten transformants were obtained and outcrossed with $w^{1118}$ (isoCJ1) for at least five generations to equilibrate genetic backgrounds to each other and to the $w^{1118}$ (isoCJ1) controls. Quantitative PCR determined that the UAS-ben ${ }^{+4-8}$ line, with the transgene inserted on the second chromosome, showed the highest level of expression for the ben ${ }^{+}$transgene. This line thus was chosen for the rescue experiments.

Northern blot analyses. RNA was isolated from adult fly heads of each genotype with Trizol according to the manufacturer's protocols (Invitrogen). PolyA + RNA was selected with oligo dT-magnetic beads (Dynal Biotech) according to the manufacturer's protocol. Northern blots were prepared using standard techniques, as in the study by DeZazzo et al. (2000). In brief, $5 \mu \mathrm{g}$ of polyA + RNA per sample was electrophoresed through a $1 \%$ agarose-formaldehyde gel via 4-morpholinepropanesulfonic acid buffer. Gels were blotted onto nylon membrane (Schleicher \& Schuell). $\mathrm{P}^{32}$-labeled probes were generated by random priming with (1) reverse transcription-PCR-generated fragments of ben, hiw, or CG5541 predicted exons or (2) an R1/HIII restriction fragment from the Rp49 gene (O'Connell and Rosbash, 1984). The resulting PCR fragments then were gel purified (Qiagen) before making radiolabeled probes.

Quantitative real-time PCR. Total RNA was isolated from $\sim 2000$ adult fly heads using Trizol total RNA isolation reagent according to the manufacturer's instructions (Invitrogen). cDNA was synthesized with Expand Reverse transcriptase (Roche Diagnostics) and oligo-dT primers. Quantitative real-time PCR was performed with the PRISM 7500 sequence detection system (Applied Biosystems). TaqMan probes for TATA-binding protein (TBP) (control) and appropriate probes for ben, hiw, and CG5541 were synthesized by Applied Biosystems. Data analysis was performed from quadplex independent samples.

Immunohistochemistry. Whole-mount immunolabeling of 2- to 3 -d-old adult brains was performed as described previously (Chiang et al., 2001, 2002). Briefly, dissected brains were fixed in $4 \%$ paraformaldehyde in PBS at room temperature overnight, transferred to $4 \%$ paraformaldehyde in PBS with 2\% Triton X-100 at a room temperature, and vacuumed for $1 \mathrm{~h}$. Fixed tissue then was blocked for $2 \mathrm{~d}$ at $4^{\circ} \mathrm{C}$ in PBS containing $2 \%$ Triton $\mathrm{X}-100$ and $10 \%$ normal goat serum (NGS) and successively incubated for $2 \mathrm{~d}$ each (with washing between) at $4^{\circ} \mathrm{C}$ in PBS containing $1 \%$ Triton X-100, 0.25\% NGS, and (1) the mouse anti-LacZ monoclonal antibody (1:200 dilution) or the rabbit anti-SCAMP polyclonal antibody (1:200 dilution) or both, or (2) a fluorescence-conjugated goat anti-rabbit $\operatorname{IgG}$ (1:200 dilution) and/or goat anti-mouse IgG (1:200 dilution). Next, the brain was cleared and mounted in FocusClear (Pacgen) and imaged with a Zeiss LSM 510 confocal microscope. For larvae brain and NMJ staining, the same procedure was followed except for changing the Triton X-100 concentration from $2 \%$ to $0.2 \%$.

Induction of the UAS-ben ${ }^{+}$transgene. Acute heat-shock induction was performed according to previously published protocols (Xia et 
al., 2005). Briefly, flies were collected and incubated at $25^{\circ} \mathrm{C}$ overnight before heat-shock treatment. The next day, flies were transferred to empty glass vials and submerged for $45 \mathrm{~min}$ in a $37^{\circ} \mathrm{C}$ water bath. After heat shock, flies were transferred to fresh food vials at $25^{\circ} \mathrm{C}$ and allowed a $3 \mathrm{~h}$ recovery period before training/testing. For experiments using $\mathrm{Gal} 80^{\text {ts }}$ (and Gal4), flies were raised at $18^{\circ} \mathrm{C}$ and kept either at $30^{\circ} \mathrm{C}$ or at $18^{\circ} \mathrm{C}$ as adults for $3 \mathrm{~d}$ before training, during training, during the retention interval and during testing.

Pavlovian olfactory learning. We quantified olfactory associative learning by subjecting 1 - to 4-d-old adult flies to a pavlovian conditioning procedure (Tully and Quinn, 1985; Tully et al., 1994; Yin et al., 1994). Typically, after one training session, memory retention in normal flies drops to near zero within $24 \mathrm{~h}$. To produce longer-lasting memory, flies were subjected to repetitive training sessions, either massed (10 sessions with no rest interval) or spaced (10 training sessions with a 15 min rest between each). After training, flies were transferred to food vials (at $18^{\circ} \mathrm{C}$ ) for $24 \mathrm{~h}$ before testing $\left(25^{\circ} \mathrm{C}\right)$ in the $\mathrm{T}$ maze. Performance indices (PIs) are normally distributed. Behavioral data were analyzed using a one-way ANOVA with subsequent pairwise planned comparisons between group means. For each experiment, the critical $p$ value ( $\alpha=0.05$ ) was adjusted for the number of pairwise comparisons made (Bonferroni's correction).

Sensorimotor responses. Olfactory acuity was quantified by exposing naive flies to each odor (octanol or methylcyclohexanol) versus air in the T maze. After $120 \mathrm{~s}$, the number of flies in each arm of the T maze was counted, and the PI was calculated for each odor as reported (Tully et al., 1994). Shock reactivity was quantified in naive flies by inserting electric grids into both arms of the T maze and delivering shock pulses to one of the arms. Flies were transported to the choice point of the T maze, allowing them to choose between the two arms. After $120 \mathrm{~s}$, the center compartment was closed, trapping flies in their respective arms. Individual PIs were calculated as for olfactory acuity. Data were analyzed as above.

Electrophysiological recordings at the larval NMJ. Synaptic currents were recorded from muscle 12 in segment 3 or 4 of third instar larvae (Jan and Jan, 1976; Singh and Wu, 1989) using two-electrode voltage clamp as described previously (Wu and Haugland, 1985; Singh and $\mathrm{Wu}, 1989$ ). Both the voltage electrode and the current electrode were filled with $3 \mathrm{M} \mathrm{KCl}$ with a resistance in the range of 5-10 $\mathrm{M} \Omega$. All electrophysiological recordings were performed at room temperature $\left(19-23^{\circ} \mathrm{C}\right)$. Stimulation of the precut motor nerve in excitatory junction current (EJC) experiments was achieved by $1 \mathrm{~ms}$ positive current stimulation of a loop of motor nerve in a suction electrode. The stimulation threshold was determined by varying stimulation intensity until the amplitude of junction currents appeared. Stimulation intensity was set 1.5 times the threshold. Both spontaneous miniature EJCs (mEJCs) and evoked EJCs were recorded in $0.4 \mathrm{mM} \mathrm{Ca}^{2+}$ Stewart saline (HL-3) (Stewart et al., 1994). All data were acquired at a clamping voltage of $-80 \mathrm{mV}$, using an Axoclamp 2B amplifier (Molecular Devices) in conjunction with pClamp6 software. Consecutive events recorded every 2 min were measured per cell using MiniAnal (Synaptosoft) and averaged to determine the mean mEJC amplitude and
B

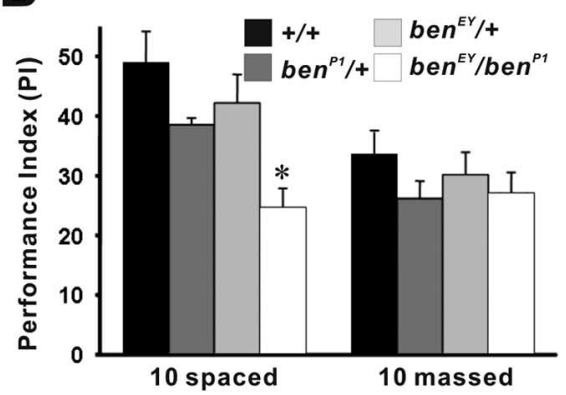

D

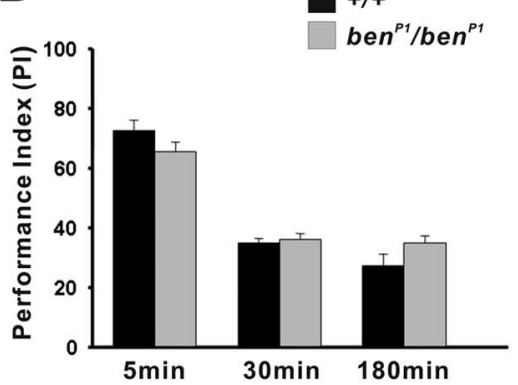

$5 \mathrm{~min} \quad 30 \mathrm{~min} 180 \mathrm{~min}$

10 spaced

Figure 1. Mutations of ben disrupt LTM formation. A, One-day memory after spaced training (10 spaced) or massed training (10 massed) was quantified in control $\left(+/+\right.$ ) and ben ${ }^{P 1} /$ ben $^{P 1}$ or ben ${ }^{E Y 08069} /$ ben $^{E Y 08069}\left(b^{E e n^{E Y}} /\right.$ ben $\left.^{E Y}\right)$ homozygous mutants. $\operatorname{ben}^{P 1} /$ ben $^{P 1}$ and ben $^{E Y} /$ ben $^{E Y}$ ). After massed training, however, mean memory scores of both homozygous mutants did not differ significantly from that of the control ( $p=0.066$ and $0.180 \mathrm{for}^{\mathrm{ben}}{ }^{P 1} / \mathrm{ben}^{P 1}$ and $\mathrm{ben}^{E Y} / \mathrm{ben}^{E Y}$, respectively). These data establish the specificity of the ben mutant for LTM rather than ARM. $n=6$ Pls for each group. B, One-day memory after spaced (10 spaced)

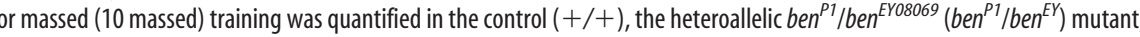
and the heterozygous ben ${ }^{P 1} /+$ or ben ${ }^{E Y 08069} /+\left(\right.$ ben $\left.^{E Y} /+\right)$ flies. After spaced training, the mean memory score for the heteroallelic fly was significantly lower than the other two heterozygous flies or the control fly $(p=0.002,0.026$, and 0.009 for $+1+$, significantly lower than the other two heterozygous flies or the control fly ( $p=0.250,0.698$, and 0.345 for $+/+$, ben ${ }^{p 1} /+$, and ben $^{\mathrm{EYO} 08069} /+$, respectively). These data establish that disruption of the ben gene per se is responsible for the LTM defect. $n=8$ PIs for each group. C, One-day memory after spaced training (10 spaced) in the control fly $(+/+)$, in the homozygous ben mutant $\left(b e n{ }^{P} / e^{p 1}\right)$, and in flies homozygous for a precise excision of the ben P-element insertion (ben $\left.{ }^{e \times 8} / b^{p e n}{ }^{e \times 8}\right)$. The mean memory score of the $b e n^{p 1} / b_{e n}{ }^{p 1}$ mutant again was significantly lower than the control $(p<0.001)$, but that for $b e n^{e \times 8} / b_{e}{ }^{e \times 8}$ flies was not $(p=0.775)$. These data confirm that the P-element insertion, and not a second-site mutation, was responsible for the LTM defect of the ben mutant. $n=6$ PIs for each group. D, Memory retention was quantified at 5,30 , and $180 \mathrm{~min}$ after one training session in the control $(+/+)$ or the $b e n^{p 1} / b e n^{p 1}$ mutant. Mutant and control flies did not differ significantly at any time point $(p=0.066,0.632$, and 0.892 for 5,30 , and $180 \mathrm{~min}$, respectively). $n=6 \mathrm{PIs}$ per group. These data indicate that learning or early memory were normal in the mutant. Error bars indicate SEM. Asterisks indicate $p<0.05$.

Table 1. Sensorimotor controls for olfactory learning in the ben mutant

\begin{tabular}{llll}
\hline & & \multicolumn{2}{l}{ Odor avoidance } \\
\cline { 3 - 4 } Genotypes & Shock reactivity $(\sim 60 \mathrm{~V})$ & OCT & MCH \\
\hline$+/+$ & $77 \pm 1$ & $66 \pm 3$ & $62 \pm 5$ \\
ben $^{P 1} /$ ben $^{P 1}$ & $80 \pm 2$ & $64 \pm 5$ & $65 \pm 2$ \\
\hline
\end{tabular}

"Task-relevant" sensorimotor responses are normal in the $b \mathrm{be}^{p 1} / \mathrm{ben}^{p 1}$ mutant. Olfactory acuity to both odors (OCT, octanol; MCH, methylcyclohexanol) and shock reactivity to footshock were evaluated in the wild-type control $(+/+)$ and the $b e n^{p 1} /$ ben $^{p 1}$ mutant. No significant differences were detected between these two genotypes.

frequency. Evoked EJCs were measured from 20 stimulations and analyzed by MiniAnal software. Statistical significance was evaluated as above.

\section{Results}

The ben mutant disrupts LTM specifically

We screened 2021 homozygous adult-viable PlacW transposants for defects in $24 \mathrm{~h}$ memory after spaced training and identified 


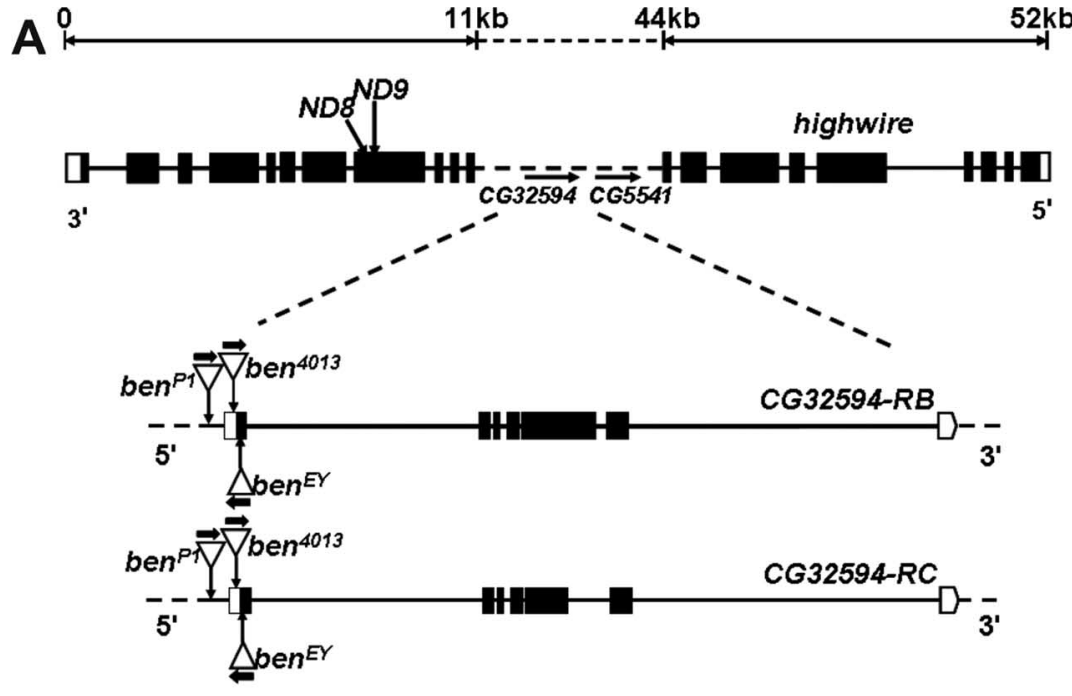

B

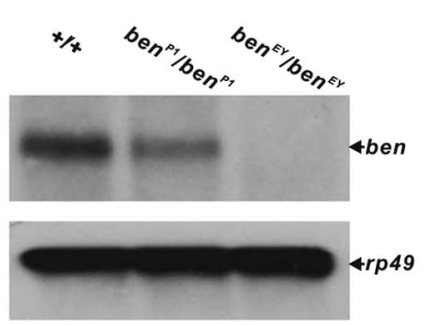

C

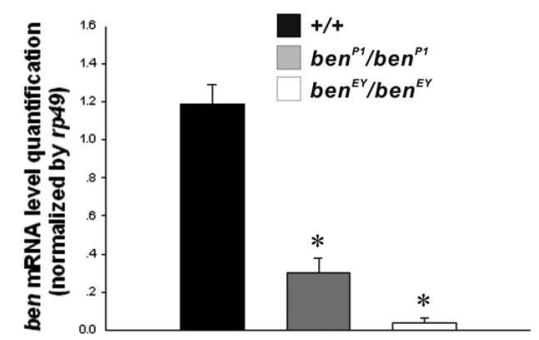

Figure 2. ben P-element alleles disrupt expression of C G32594. A, The genomic structure of C G32594 located along with C G5541 within an intron of highwire. Also shown in expanded view are (1) the PlacW insertion site $\left(b e n^{P 1}\right)$ of the ben ${ }^{P 1}$ mutant, (2) the PEPgy2 insertion site (ben ${ }^{E Y}$ ) of the ben ${ }^{E Y 08069}$ mutant, and (3) the PGawB insertion (ben ${ }^{4013}$ ) of the ben ${ }^{G a l 4}$ mutant. The directions of enhancer-driven transcription within each P element are indicated by an arrow. CG32594 (ben) resides in the $33 \mathrm{~kb}$ intron of the highwire (hiw) gene but is transcribed in the opposite direction, along with (G5541, which lies 3' of ben. Two null mutations of hiw, hiw ${ }^{N D 8}$ (ND8) and hiw ${ }^{N D 9}$ (ND9), also are indicated. B, Northern blot analysis of the ben transcript in the control fly $(+/+)$, the ben ${ }^{P 1} /$ ben $^{P 1}$ mutant, and the ben ${ }^{E Y 08069} /$ ben $^{E Y 08069}\left(\right.$ ben $^{E Y} /$ ben $^{E Y}$ ) mutant. mRNA expression is almost undetectable in the $b e n^{E Y 08069} /$ ben $^{E Y O 8069}$ mutant and is dramatically reduced in the ben ${ }^{P 1} /$ $b e n^{P 1}$ mutant compared with the control fly. In contrast, mRNA expression of a control gene, $r p 49$, is similar among mutant and control genotypes, indicating that similar total amounts of mRNA were loaded into each lane. C, Quantitative analysis of mRNA in the control fly $(+/+)$, the ben ${ }^{P 1} /$ ben $^{P 1}$ mutant, and the ben ${ }^{E Y 08069} /$ ben $^{E Y 08069}\left(\right.$ ben $^{E Y} /$ ben $^{E Y}$ ) mutant from independent samples. Both the homozygous ben ${ }^{P 1} / b_{e n}{ }^{P 1}$ mutant and the $b e n^{E Y} / b e n^{E Y}$ mutant showed significantly lower expression of ben than the control fly ( $p<0.001$ for both homozygous mutants). Error bars indicate SEM. Asterisks indicate $p<0.05$.

strain 20816039 as one of 11 candidate mutants (Lu et al., 2007; Qian et al., 2007). We named this mutant strain ben, which means "stupid" in Mandarin, and specified the mutation as $b e n^{P 1}$. Whereas $1 \mathrm{~d}$ memory after spaced training was impaired significantly in the ben mutant, $1 \mathrm{~d}$ memory after massed training (ARM) was not (Fig. $1 A$ ), suggesting that LTM but not ARM was disrupted (Tully et al., 1994). Memory retention at 5, 30, or 180 min after a single training session also was normal in ben mutants (Fig. 1D), further indicating that early memory (short-term memory and middle-term memory) also was not affected (Tully et al., 1996).

As a result of the molecular-genetic characterization of the ben mutant (see below), we identified a second putative allele in strain $E Y 08069\left(b e n^{E Y}\right) . b e n^{E Y}$ and $b e n^{P 1}$ each were recessive to $b e n^{+}$, and they failed to complement each other for $1 \mathrm{~d}$ memory after spaced training (Fig. $1 B$ ). In contrast, ben ${ }^{P I}$ complemented two different alleles of hiw (Fig. S1 $A, B$, available at www.jneurosci.org as supplemental material). We also generated a precise excision of $b e n^{P 1}$ and showed a reversion of the mutant LTM defect in this ben ${ }^{e x 8}$ homozygote (Fig. 1C). Finally, normal performance of the ben $^{P 1}$ mutant 5 min after training suggested that it also had normal sensorimotor responses to odors (positive and negative conditioned stimuli) and footshock (unconditioned stimulus). Nonetheless, we assessed olfactory acuity and shock reactivity directly, confirming that these task-relevant behavioral responses were normal in the ben mutant (Table 1). Together, these behavior-genetic data establish that disruption of ben impairs LTM formation specifically.

\section{ben $^{P 1}$ disrupts the CG32594 transcript}

Plasmid rescue of the PlacW transposon in the $b e n^{P 1}$ mutant, followed by sequencing of genomic DNA flanking the PlacW insertion site, identified the $b e n^{P 1}$ PlacW to be inserted $21 \mathrm{bp} 5^{\prime}$ of the CG32594 transcript. Functional analysis of ben was complicated by the fact that ben and CG5541 both reside in the largest intron $(\sim 33 \mathrm{~kb})$ of highwire, which is involved in synaptic development and function (Fig. 2A) (Wan et al., 2000; Wu et al., 2005). We analyzed these three genes' expression levels by Northern blot analysis and real-time PCR (Fig. $2 B, C$; Fig. S2, available at www.jneurosci.org as supplemental material). The mRNA levels of ben were decreased significantly in the $b e n^{P 1}$ homozygote and were nearly abolished in the ben ${ }^{E Y 08069}$ homozygote, which has an EPgy2 element inserted in the first exon (Bellen et al., 2004). In contrast, mRNA levels of hiw and CG5541 were normal in $b e n^{P 1}$ or ben ${ }^{E Y}$ homozygotes (Fig. S2, available at www.jneurosci.org as supplemental material), suggesting the ben ${ }^{P 1} \mathrm{PlacW}$ insertional mutation specifically disrupts the ben gene and not its neighboring genes.

We have not yet been able to identify antibodies specific to BEN even after several attempts; consequently, we have not determined the subcellular distribution of BEN. Nevertheless, we were able to assess in which neurons of the CNS ben likely is expressed by using the lac $Z$ reporter protein within the PlacW transposon of the $b e n^{P 1}$ mutant, along with the Gal4 reporter protein in strain $4013\left(\right.$ ben $\left.^{\text {Gal }}\right)$, which contains a PGawB transposon inserted in the $5^{\prime}$ untranslated region (UTR) of ben (Fig. $3 A, B$ ). In contrast to the negative signal observed in wild-type flies, immunostaining for both antiLacZ and anti-GAL4 in the corresponding flies revealed widespread expression in the adult brain, with higher levels in $\mathrm{MB}$ Kenyon cells (Fig. S3 B, C, available at www.jneurosci.org as supplemental material). Merged confocal images of the antiLacZ (perinuclear) and anti-GAL4 (cytosolic) signals showed coexpression of these reporter proteins in some Kenyon cells (Fig. $3 A$ ). Thus, the overlapping expression of the $b e n^{P 1}$ PlacZ 
A

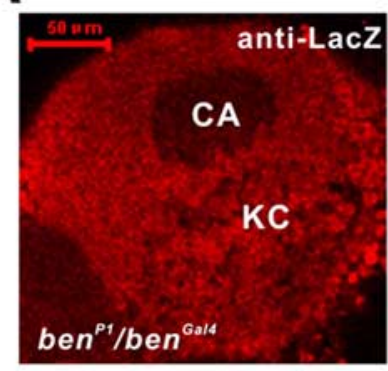

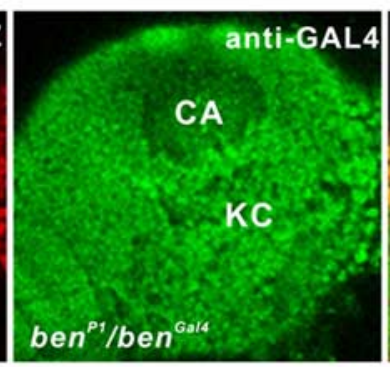

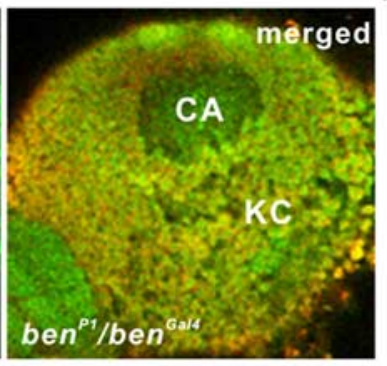

B

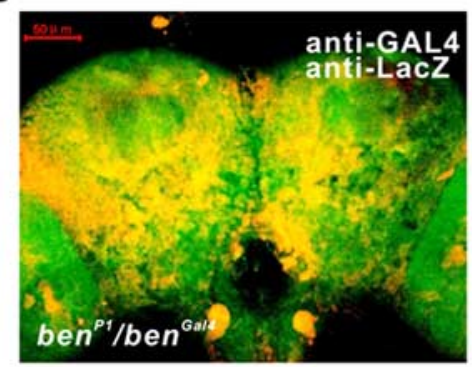

C

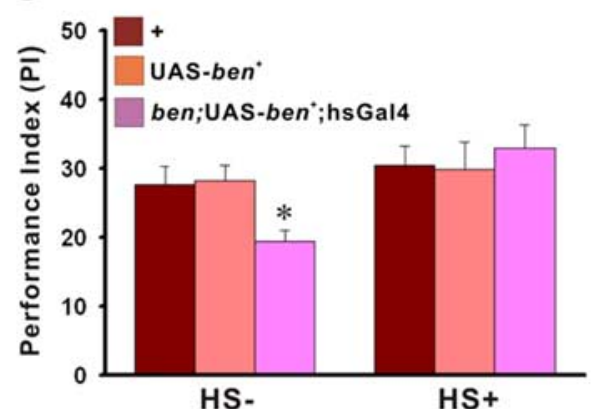

$\mathbf{F}$
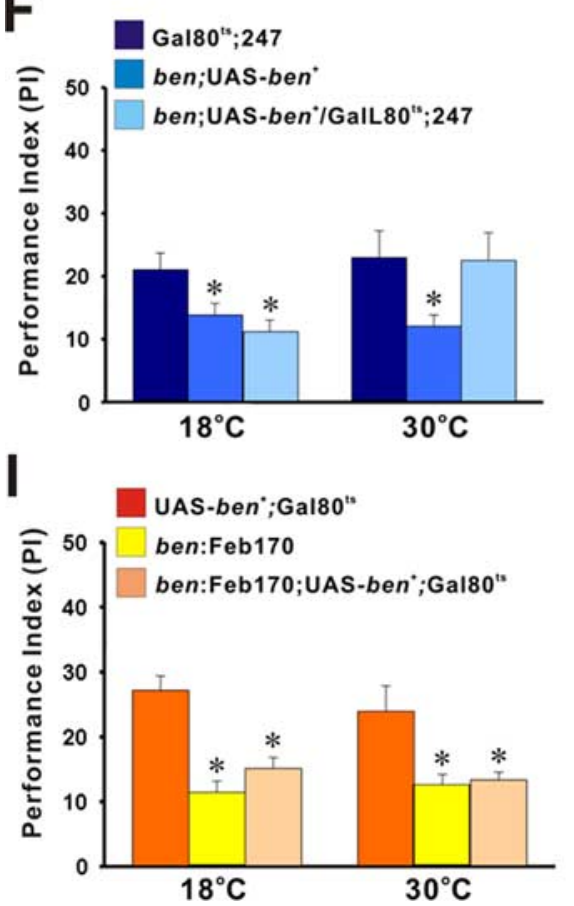

D

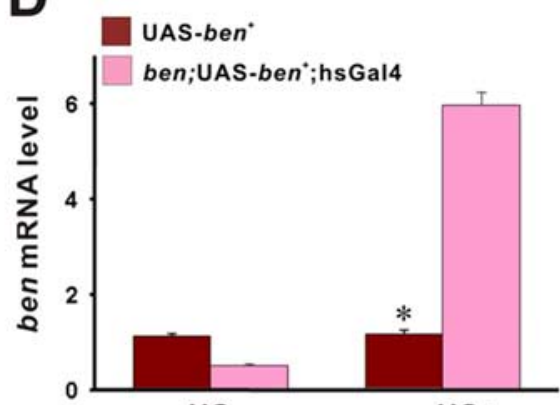

HS-

G $7739 ; G a 180 "$
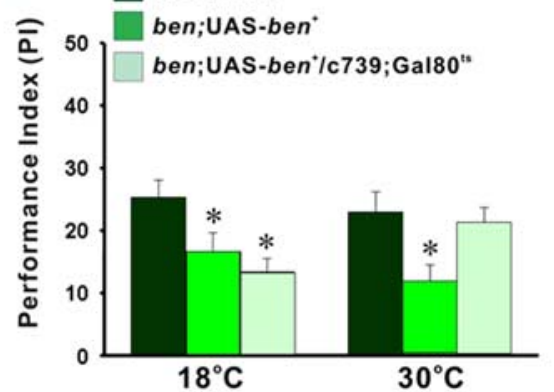

J

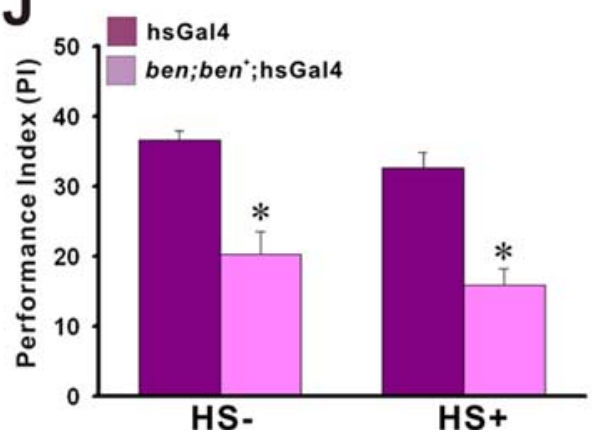

E
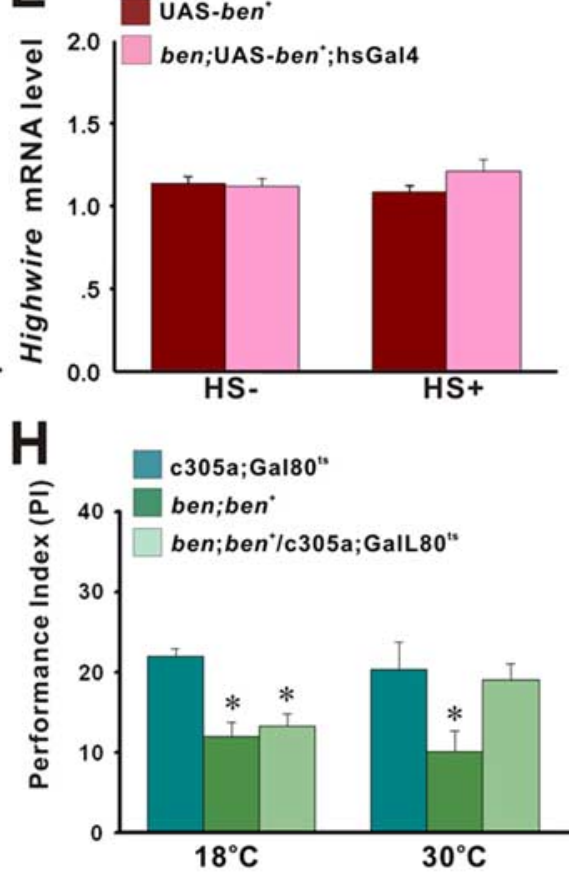

Figure 3. LTM defects of ben mutant are rescued by acute induction of transgenic UAS-ben ${ }^{+4-8}$ in MB. $A$, The LacZ reporter gene within the ben ${ }^{P 1}$ transposon and the GAL4 reporter gene within the ben ${ }^{4013}$ reporter gene were expressed together in the ben ${ }^{P 1} / 4013\left(\right.$ ben $^{P 1} /$ ben $^{G a l 4}$ ) heteroallelic mutant. Immunostaining reveals anti-LacZ (red, perinuclear) and anti-GAL4 (green, cytosolic) confocal signals in most, if not all, Kenyon cells (KC) of the MB. The merged signals (yellow) clearly show coexpression throughout the KC bodies. (Because the GAL4 reporter gene does not carry a nuclear localization signal, its expression extends throughout the KC neuropil, unlike the lacZ reporter.) CA, Calyx. Scale bar, $50 \mu m$. $B$, The anti-LacZ (red) and anti-GAL4 (green) confocal signals throughout the adult brain of the ben ${ }^{P 1} / 4013$ (ben ${ }^{P 1} /$ ben $^{\text {Gal4 }}$ ) mutant were merged (yellow), also revealing widespread colocalization in the central brain outside of MBs. Scale bar, $50 \mu \mathrm{m}$. C, One-day memory after spaced (10 spaced) training was quantified in wild-type control $+/+$ males $(+)$, control $+/ \mathrm{Y}$;UAS-ben ${ }^{+4-8} ;+/+$ males (UAS-ben ${ }^{+}$), and transgenic mutant ben/Y;UAS-ben ${ }^{+4-8} /+;$,hsGal4/+ males (ben; UAS-ben ${ }^{+}$;hsGal4) with (HS + ) or without (HS-) heat shock $3 \mathrm{~h}$ before training. Without heat shock, the mean memory score of the transgenic mutant was significantly lower than that of the control flies ( $p=0.033$ ). With heat shock, however, the mean memory score of the transgenic mutant and the control did not differ ( $p=0.847)$. These data established that universal induction of the ben + transgene in adult brain is sufficient to rescue the LTM defect in the ben mutant. $n=8$ PIs for each group. $D$, Quantitative PCR of the ben transcript in control $+/ Y$; UAS-ben ${ }^{+4-8} ;+/+$ males (UAS-ben ${ }^{+}$) and transgenic mutant ben/Y;UAS-ben ${ }^{+4-8} /+;$ hsGal4/+ males (ben;UAS-ben ${ }^{+} ;$hs-Gal4) $3 \mathrm{~h}$ after heat shock (HS + ) revealed a significantly higher level of ben mRNA expression in the transgenic mutant than in the control $(p<0.001)$. Without heat shock (HS - ), however, the ben mRNA level is significantly lower than normal ( $p<0.001)$. mRNA values among all genotypes were normalized to TBP mRNA levels. $n=4$ determinations for each group. $\boldsymbol{E}$, Quantitative PCR of the highwire transcript in control $+/ Y ; U A S-b e n{ }^{+4-8} ;+/+$ males $\left(U_{A S}\right.$-ben $\left.{ }^{+}\right)$and transgenic mutant ben/Y; UAS-ben ${ }^{+4-8} /+;$ hsGal $4 /+$ males (ben; UAS-ben ${ }^{+}$; hs-Gal4). In contrast to ben mRNA levels, hiw mRNA levels were similar between mutant and control with $(\mathrm{HS}+$ ) or without (HS-) heat shock ( $p=0.194$ and 0.778 , respectively). mRNA values among all genotypes were normalized to TBP mRNA levels. $n=4$ (Figure legend continues.) 
and ben ${ }^{\text {Gal4 }} \mathrm{PGawB}$ reporter genes suggest that ben is expressed in Kenyon cells of the MB.

\section{Induced expression in the adult brain, or restricted expression in the $\mathrm{MB}$, of a $\mathrm{ben}^{+}$transgene is sufficient to rescue the ben LTM defect}

To establish an acute role for ben in LTM, we first attempted rescue of the ben mutant LTM defect by driving the expression of a UAS-ben ${ }^{+}$transgene (UAS-ben ${ }^{+4-8}$ ) with a hs-Gal4 driver, which induces rapid, ubiquitous expression of $\mathrm{ben}^{+}$in the adult brain after heat shock. Flies were either heat shocked $\left(25-37^{\circ} \mathrm{C}\right.$ for $45 \mathrm{~min}$ with $3 \mathrm{~h}$ recovery) or kept at $25^{\circ} \mathrm{C}$ during the experimental procedure, and $1 \mathrm{~d}$ memory after spaced training was quantified for all groups. In the absence of heat shock, $1 \mathrm{~d}$ memory in the ben;UAS-ben ${ }^{+}$;hs-Gal4 transgenic mutant males was significantly lower than that in the UAS-ben ${ }^{+4}$ control males (Fig. 3C). When trained $3 \mathrm{~h}$ after heat shock, in contrast, transgenic mutants and controls showed similar $1 \mathrm{~d}$ memory (Fig. 3C). Heat shock produced no significant effects in wild-type flies (Fig S4, available at www.jneurosci.org as supplemental material), thereby allowing the conclusion that heat shock-induced expression of UAS-ben ${ }^{+}$produced a specific rescue of the mutant LTM defect.

Consistent with these behavioral rescue data, ben mRNA expression in the absence of heat shock was significantly lower in ben;UAS-ben ${ }^{+}$;hs-Gal4 transgenic mutant males than in the UAS-ben ${ }^{+}$control males and was elevated dramatically in transgenic mutants $3 \mathrm{~h}$ after heat shock (Fig. 3D). Given ben's location within an intron of hiw, we also evaluated whether heat shock affected hiw mRNA expression levels in transgenic mutant or control males; it did not (Fig. 3E).

Having established a physiological, rather than a developmental, role for ben during adult LTM formation, we returned to the question of where in the adult brain ben's function might be critical for LTM formation. The widespread expression patterns of the $b e n^{P 1}$ and $b e n^{\text {Gal4 }}$ reporter genes in the adult brain did not provide any clues as to where ben might be required for LTM formation. Based on the literature, however, two anatomical regions seemed possible: MBs (Connolly et al., 1996; Zars et al., 2000; Dubnau et al., 2001; Pascual and Preat, 2001; McGuire et al., 2003; Krashes et al., 2007; Lu et al., 2007; Qian et al., 2007) or the EB of the central complex (Wu et al., 2007). We first used the Gal4 driver 247, which expresses strongly in $\alpha / \beta$ and $\gamma$ lobes and weakly in $\alpha^{\prime} / \beta^{\prime}$ lobes, of MB (Schwaerzel et al., 2002). We combined 247 with tub-Gal80 ${ }^{\text {ts }}$ to control UAS-ben ${ }^{+}$transgene expression temporally as well as spatially (McGuire et al., 2003). One-day memory after spaced training was quantified for all groups. When trained and tested at $18^{\circ} \mathrm{C}\left(\right.$ GAL80 ${ }^{\text {ts }}$ inhibits GAL4), $1 \mathrm{~d}$ memory in ben;UAS-ben ${ }^{+} / \mathrm{Gal} 0^{\mathrm{ts}} ; 247$ transgenic mutant males and in the ben;UAS-ben ${ }^{+}$control mutant males was significantly lower and than in Gal80 ${ }^{\text {ts }} ; 247$ control males (Fig. $3 F$ ). When trained and tested at $30^{\circ} \mathrm{C}$ (GAL80 ${ }^{\text {ts }}$ fails to inhibit GAL4), $1 \mathrm{~d}$ memory in the transgenic mutant males was significantly higher than in mutant control males and was not different from the wild-type control males (Fig. $3 F$ ). A temperature shift from 18 to $30^{\circ} \mathrm{C}$ in control flies produced no effects on $1 \mathrm{~d}$ memory (data not shown), therefore suggesting a specific effect of the UAS-ben ${ }^{+}$transgene.

This initial result on rescue of the mutant LTM defect with transgenic $b_{e n}{ }^{+}$expression restricted to MBs was confirmed using two additional Gal4 drivers with preferential expression in MBs. With both $c 739$ and $c 305 a$ (Krashes et al., 2007; Wang et al., 2008), we again saw induced rescue of the ben LTM defect (Fig. 3G,H). We also induced expression of UAS-ben ${ }^{+}$ in the EB of the central complex by using the Gal4 driver

$\leftarrow$

(Figure legend continued.) determinations for each group. $\boldsymbol{F}, 0$ ne-day memory after spaced training (10 spaced) was quantified in control $+/ \mathrm{Y} ;+/ \mathrm{GAL} 80^{\text {ts }} ;+/ 247$ males $\left(\mathrm{GAL} 80^{\text {ts }} ; 247\right)$,

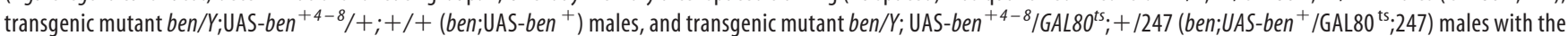
ben ${ }^{+}$transgene expression controlled by a the $247 \mathrm{MB}-\mathrm{GAL} 4$ driver and the $\mathrm{GAL} 80^{\mathrm{ts}} \mathrm{GAL} 4$ repressor. Flies were raised at the permissive temperature ( $18^{\circ} \mathrm{C}$ ), and memory was evaluated either at the same temperature or after $3 \mathrm{~d}$ at the restrictive temperature $\left(30^{\circ} \mathrm{C}\right)$. At the permissive temperature, when $\mathrm{GAL} 80^{\mathrm{ts}}$ successfully represses $\mathrm{MB}$ - $\mathrm{GAL} 4$-driven expression of UAS-ben $^{+}$, mean memory scores for the ben;UAS-ben ${ }^{+} / \mathrm{GAL} 80^{\text {ts }} ; 247$ and ben;UAS-ben ${ }^{+}$transgenic mutant males both were significantly lower than that for the GAL $80^{\text {ts }} ; 247$ control flies ( $p<0.001$ and $p=0.010$, respectively). At the restrictive temperature, when GAL $80^{\text {ts }}$ fails to repress MB-GAL4-driven expression of UAS-ben ${ }^{+}$, mean memory scores for the ben;UAS-ben ${ }^{+} / \mathrm{GAL} 80^{\text {ts }} ; 247$ and ben;UAS-ben ${ }^{+}$transgenic mutant males were similar to, or significantly lower than, that for the GAL80 ${ }^{\text {s. }} ; 247$ control males $(p=0.830$ and $p=0.040$, respectively). These data establish that acute induction of the ben ${ }^{+}$transgene in MBs is sufficient to rescue the LTM defect in the ben adult mutant. $n=6$ PIs for each group. $\mathbf{G}, 0$ ne-day memory after spaced training (10 spaced) was quantified in control $+/ \mathrm{Y} ;+/ \mathrm{c} 739 ;+/ G A L 80^{\text {ts }}$ males $\left(\mathrm{c} 739 ; \mathrm{GAL} 80^{\text {ts }}\right)$, transgenic mutant ben/Y;UAS-ben ${ }^{+4-8} /+;+/+$ males $($ ben; UAS-ben $^{+}$), and transgenic mutant ben/Y;UAS-ben ${ }^{+4-8} / \mathrm{c} 739 ; / G A L 80^{\text {ts }} /+$ males (ben;UAS-ben ${ }^{+} /\left(739 ; G A L 80^{t s}\right.$ ) with the ben ${ }^{+}$transgene expression controlled by a second MB-GAL4 driver, $\mathrm{C} 739$, and the GAL80 ${ }^{\text {ts }} \mathrm{GAL} 4$ repressor. At the permissive temperature, mean memory scores for the ben;UAS-ben ${ }^{+} / \mathrm{GAL} 80^{\mathrm{ts}} ; \mathrm{C} 739$ and ben;UAS-ben ${ }^{+}$transgenic mutant males were significantly lower than that for the $\mathrm{GAL} 80^{\mathrm{ts}}, \mathrm{c} 739$ control male ( $p=0.005$ and 0.037 , respectively). At the restrictive temperature, mean memory scores for the ben; UAS-ben ${ }^{+} /$ $\mathrm{GAL} 80^{\mathrm{ts}} ; \mathrm{c} 739$ and ben;UAS-ben ${ }^{+}$transgenic mutant males were similar to, and significantly lower than, that for the GAL $80^{\text {ts }} ; \mathrm{c} 739 \mathrm{control}$ male ( $p=0.069$ and $p=0.002$, respectively). These data also confirm that acute induction of the ben ${ }^{+}$transgene in MBs is sufficient to rescue the LTM defect of the ben mutant. $n=6$ PIs for each group. $\boldsymbol{H}, 0$ ne-day memory after spaced training (10 spaced) was quantified in control $+/ \mathrm{Y} ;+/ \mathrm{c305a} ;+/ \mathrm{GAL} 80^{\text {ts }}$ males $\left(\mathrm{c} 305 \mathrm{a} ; \mathrm{GAL} 80^{\text {ts }}\right)$, transgenic mutant ben/Y;UAS-ben ${ }^{+4}-8 /+;+/+$ males $\left(\right.$ ben; $\mathrm{UAS}-$ ben $\left.{ }^{+}\right)$, and

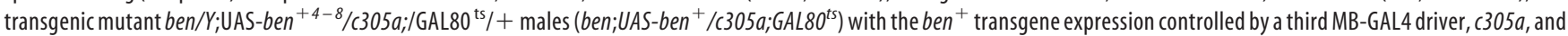
the $\mathrm{GAL} 80^{\text {ts }} \mathrm{GAL} 4$ repressor. At the permissive temperature, mean memory scores for the ben;UAS-ben ${ }^{+} / \mathrm{C}^{\circ} 305 \mathrm{a} ; \mathrm{GAL} 80^{\text {ts }}$ and ben;UAS-ben ${ }^{+}$transgenic mutant males were significantly lower than that for the $\mathrm{C} 305 \mathrm{a} ; \mathrm{GAL} 80^{\mathrm{ts}}$ control male ( $p=0.005$ and 0.037 , respectively). At the restrictive temperature, mean memory scores for the ben; $\mathrm{UAS}-$ ben ${ }^{+} / \mathrm{C} 305 \mathrm{a} ; \mathrm{GAL} 80^{\mathrm{ts}}$ and ben;UAS-ben ${ }^{+}$transgenic mutant males were similar to, and significantly lower than, that for the c $305 \mathrm{a} ; \mathrm{GAL} 80^{\mathrm{ts}}$ control male ( $p=0.069$ and $p=0.002$, respectively). These data confirm yet again that acute induction of the ben ${ }^{+}$transgene in MBs is sufficient to rescue the LTM defect of the ben mutant. $n=6 \mathrm{PIs}$ for each group. $I$, In contrast, $1 \mathrm{~d}$ memory after spaced training (10 spaced) was quantified in the control $+/ Y ;$ UAS-ben ${ }^{+4-8} /+;+/ G_{\text {Gal } 80}{ }^{\text {ts }}$ male (UAS-ben ${ }^{+} ;$Gal $\left.80^{\text {ts }}\right)$, transgenic mutant ben,Feb170/Y; $+/+;+/+$ males, $($ ben:

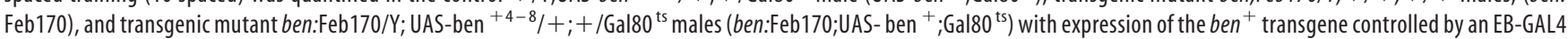
driver Feb170 and the GAL8 ${ }^{\text {ts }} \mathrm{GAL} 4$ repressor. At the permissive temperature, mean memory scores for the ben:Feb170 and UAS-ben ${ }^{+}$; Gal $80^{\text {ts }}$ transgenic mutant males remained significantly lower than that for the UAS-ben ${ }^{+} ; \mathrm{Gal} 80{ }^{\text {ts }}$ control male ( $p=0.004$ and 0.038 , respectively). At the restrictive temperature, mean memory scores for the ben:Feb170 and UAS-ben $^{+} ; \mathrm{Gal} 80^{\text {ts }}$ transgenic mutant males also remained significantly lower than that for the UAS-ben ${ }^{+} ;$Gal $80^{\text {ts }}$ control male ( $p=0.028$ and 0.024 , respectively). These data show that acute induction of the ben ${ }^{+}$transgene in EBs is not sufficient to rescue the LTM defect of the ben mutant. $n=6 \mathrm{Pls}$ for each group. $J, 0$ ne-day memory after spaced (10 spaced)

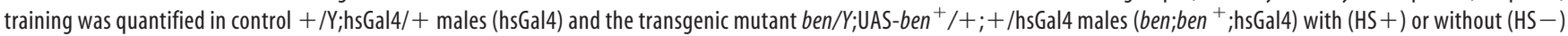
heat shock $1 \mathrm{~h}$ before testing. The mean memory scores are significantly lower in the transgenic mutant either with heat shock or without heat shock compared with the corresponding control male ( $p<0.001$ for both). These data established that pan-neural induction of the ben ${ }^{+}$transgene in adults during memory retrieval is not sufficient to rescue the LTM defect of the ben mutant. $n=8 \mathrm{PIs}$ for each group. Error bars indicate SEM. Asterisks indicate $p<0.05$. 

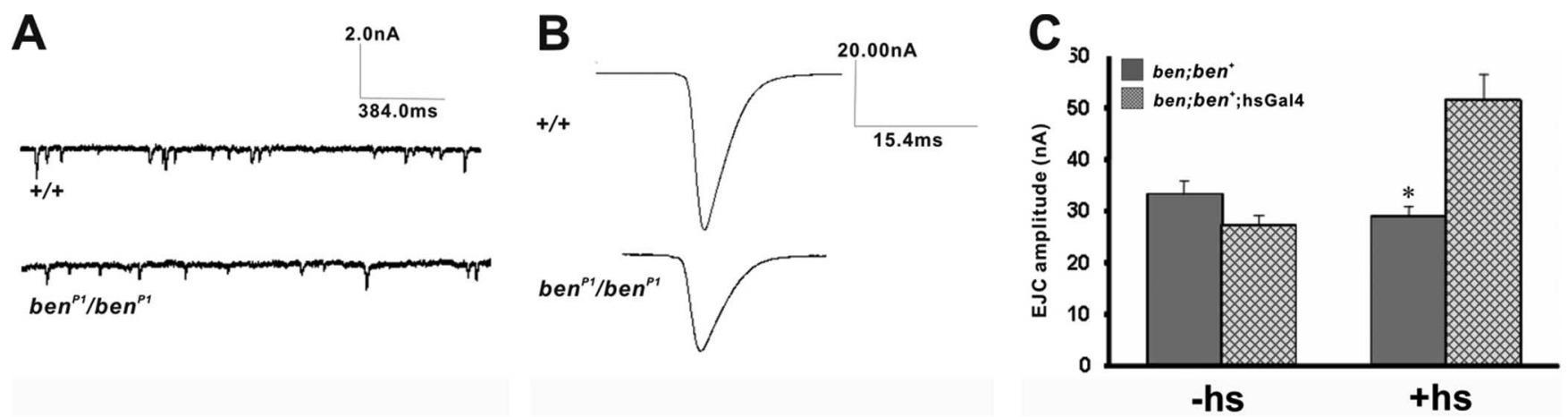

Figure 4. ben functions together with Scamp during synaptic transmission at the larval NMJ. $A$, Representative traces of spontaneous mEJCs were recorded from muscle 12 on larval segment $3 / 4$ in wild-type control $(+/+)$ or ben $^{p 1} /$ ben $^{P 1}$ mutant larvae. Similar mEJC amplitudes and frequencies were observed between these two genotypes. Calibration: $2 \mathrm{nA}, 384.0 \mathrm{~ms}$. $\boldsymbol{B}$, Representative traces of evoked EJCs were recorded from muscle 12 on larval segment $3 / 4$ in wild-type control $(+/+)$ or the ben ${ }^{P 1} /$ ben $^{P 1}$ mutant. Mutant traces obviously were lower than those for the control. Calibration: $20 \mathrm{nA}, 15.4$ ms. C, Evoked EJC amplitude was quantified in transgenic mutant ben $/ Y$;UAS-ben ${ }^{+4-8} /+$; hsGal4/+ males (ben; ben ${ }^{+}$; hsGal4) and transgenic control mutant ben/Y;UASben $^{+4-8} /+$ males $\left(\right.$ ben; ben $\left.{ }^{+}\right)$. Each genotype was treated either with $(+\mathrm{hs})$ or without $(-\mathrm{hs})$ heat shock. Without heat shock, evoked EJC amplitudes were similarly low $(p=0.222)$. With heat shock, however, the evoked EJC amplitude in the transgenic mutant ben/Y;UAS-ben ${ }^{+4-8} /+;$ hsGal $4 /+$ males was significantly higher than that in transgenic control ben/Y;UAS-ben ${ }^{+4-8} /+$ mutant males $(p<0.001)$. These data establish that pan-neural induction of the ben ${ }^{+}$transgene is sufficient to rescue the synaptic transmission defect of the ben mutant. $n=10$ segment recordings for each group. Error bars indicate SEM. Asterisks indicate $p<0.05$.

Feb170 but did not observe any rescue of the mutant LTM defect (Fig. 3I) (Wu et al., 2007, but see Krashes and Waddell, 2008). Finally, we investigated ben's role during memory retrieval rather than memory storage. Transgenic ben;hs-Gal4; $\mathrm{UAS}$ ben ${ }^{+}$mutant males were heat shocked (from 25 to $37^{\circ} \mathrm{C}$ for $45 \mathrm{~min}$ ) and then were allowed to recover at $25^{\circ} \mathrm{C}$ for $1 \mathrm{~h}$ right before evaluating $1 \mathrm{~d}$ memory after spaced training. Transgenic ben;UAS-ben ${ }^{+}$; hs-Gal4 mutant males showed similar, defective $1 \mathrm{~d}$ memory after heat shock (or when not heat shocked) compared with UAS-ben ${ }^{+4-8}$ control males (Fig. 3J). Together, these observations suggest that ben functions specifically in the adult MB (most likely in $\alpha / \beta$ an $\alpha^{\prime} / \beta^{\prime}$ lobes) during LTM consolidation.

\section{The ben mutant disrupts synaptic transmission at the larval NMJ}

Other memory mutants have demonstrated defects in synaptic plasticity at the larval NMJ (Saitoe, 2001). The $b e n^{P 1}$ transposon is inserted in a large intron of hiw, however, mutations of which are known to disrupt synaptic structure at the larval NMJ (Wan et al., 2000; Wu et al., 2005). Consequently, we first had to rule out any disruptive effects that the $b e n^{P 1}$ mutation may have exerted on hiw function. We clearly detected abnormally high numbers of branches and boutons in homozygous hiw ${ }^{N D 9}$ mutants. Such synaptic structure was normal in the $b e n^{P 1}$ mutant, however, which also complemented the defects of hiw ${ }^{N D 9}$ (Fig. S1C,D, available at www.jneurosci.org as supplemental material). Along with our results from genetic complementation for LTM, these data also confirm that these ben mutations do not affect hiw function.

We next evaluated synaptic function in the ben mutants by recording from muscle 12 (segment 3 or 4 ) of the third instar larva (Jan and Jan, 1976; Singh and Wu, 1989). Postsynaptic responses to both spontaneous and evoked transmitter release were quantified. The mean amplitude of spontaneous mEJCs, also called quantal size, typically is considered to be a measure of postsynaptic sensitivity to transmitter. The mean amplitude of evoked EJCs, in contrast, depends on both postsynaptic receptor function and the amount of transmitter released from the presynaptic terminal. We found the mean mEJC am- plitude for $b e n^{P 1}$ homozygotes to be normal (Fig. $4 A$ ), and the mean mEJC frequency for this genotype was slightly lower than normal, but not significantly so (Fig. $4 A$ ). In contrast, the mean evoked EJC for $b e n^{P 1}$ homozygotes was significantly lower than normal, by nearly $35 \%$ (Fig. 4 B). Thus, the quantal content (number of vesicles released, which is estimated by dividing the mean EJC amplitude by the mean mEJC amplitude) at the synapse of the $b e n^{P 1}$ mutant was only $\sim 65 \%$ of wild type. This defect in evoked EJCs also was apparent in the ben; UAS-ben ${ }^{+}$; hs-Gal4 transgenic mutant and the ben;UASben $^{+}$mutant control in the absence of heat shock (Fig. 4C). When measured $3 \mathrm{~h}$ after a 45 min heat shock, however, the mean amplitude of evoked EJCs was rescued fully (i.e., normal) in the transgenic mutant (Fig. 4C). Considering quantal content is an indication of presynaptic function (Landmesser, 1998), our data suggest that ben is required presynaptically during synaptic transmission. Given our parallel behavioral rescue for LTM, our data suggest that a similar defect in synaptic transmission in the CNS may underlie the LTM impairment of the ben mutant.

\section{BEN and SCAMP interact functionally to disrupt LTM formation and synaptic transmission}

Guided by the NMJ defect of the ben mutant, we perused BioGrid, a public database of gene interactions (Stark et al., 2006). We discovered from yeast two-hybrid experiments that BEN interacts with CdsA, which itself interacts with SCAMP (Giot et al., 2003). The Scamp gene encodes a secretory carrier membrane protein family member that has been shown in Drosophila to be involved in vesicle trafficking and neurotransmitter release (Hubbard et al., 2000; Littleton, 2000).

Based on this bioinformatics, we evaluated a functional connection between ben and Scamp using a classic test for genetic epistasis, quantifying $1 \mathrm{~d}$ memory after spaced training in $b^{2} n^{P 1} /$ Scamp ${ }^{E P}$ or $b e n^{E Y} / S_{c a m p}{ }^{E P}$ double heterozygotes. Although the Scamp mutation alone appeared to be recessive (LTM was normal), $1 \mathrm{~d}$ memory after spaced training was significantly lower than normal in both double heterozygotes (Fig. 5A). This defect also appeared specific for LTM, because $1 \mathrm{~d}$ memory after massed training and 5 min memory after one training session were nor- 
A
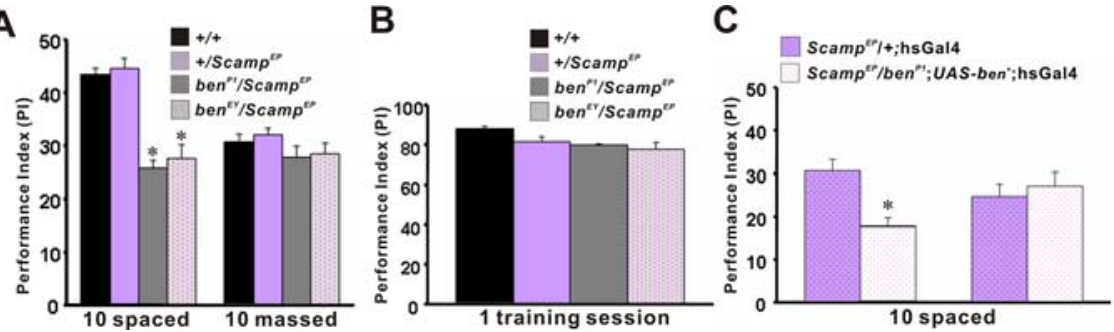

Figure 5. ben and Scamp function together during LTM formation. $\boldsymbol{A}$, One-day memory after spaced (10 spaced) or massed (10 massed) training was quantified in the wild-type control $(+/+)$, the $+/ S c a m p{ }^{E P}$ heterozygote, and the $b e n^{P 1} / S_{\text {camp }} p^{E P}$ or $b e n^{E Y} / S c a m p^{E P}$ double heterozygotes. After spaced training, the mean memory score for the $+/ S c a m p^{E P}$ heterozygote did not differ from that of the control ( $p=0.720$ ), whereas mean memory scores for both double heterozygotes (ben ${ }^{P 1} / S_{\text {camp }}{ }^{E P}$ or $b e n^{E Y} / S_{\text {camp }}{ }^{E P}$ ) were significantly lower than normal $(p<0.001$ for both). After massed training, mean memory scores did not differ among all four genotypes $(p>0.05)$. These data establish that ben functions together Scamp specifically during LTM formation. $n=8$ PIs for each group. $\boldsymbol{B}$, Memory retention was quantified 5 min after one training session in the wild-type control $(+/+)$, the $+/$ Scamp $^{E P}$ heterozygote, and the ben ${ }^{P 1} / S_{\mathrm{S} a m p}{ }^{E P}$ or $b n^{E Y} / S_{C a m p}{ }^{E P}$ double heterozygotes. No significant differences were detected among all the genotypes $(p>0.05) . n=$ 8 Pls per fly group. C, One-day memory after spaced training (10 spaced) was quantified in the control Scamp $p^{E P} /+$; hsGal4/+ (Scamp ${ }^{E P} /+;$ hsGal4 $)$ and the transgenic Scamp $^{E P} /$ ben $^{\mathrm{P1}} ; \mathrm{UAS}-$ ben $^{+4-8} /+;$ hsGal $4 /+$ double heterozygote $\left(\mathrm{Scamp}^{E P} / \mathrm{ben}^{\mathrm{P} 1} ; \mathrm{UAS}-\mathrm{ben}^{+} ; \mathrm{hsGal} 4\right)$. These two genotypes were trained without heat shock or $3 \mathrm{~h}$ after heat shock. Without heat shock, the mean memory score of the transgenic double heterozygote was significantly lower than the control ( $p=0.002$ ). With heat shock, however, mean memory scores between these two genotypes did not differ ( $p=$ 0.231). These data establish that pan-neural induction of the $b e n^{+}$transgene is sufficient to rescue the LTM defect produced by an epistatic interaction between the Scamp $p^{E P}$ and ben ${ }^{\mathrm{P} 1}$ mutations. $n=8$ PIs for each group. Error bars indicate SEM. Asterisks indicate $p<0.05$.

mal in both double heterozygotes (Fig. $5 A, B$ ). Importantly, this epistatic LTM defect could be rescued in $b e n^{P 1} / S c a m p^{E P}$; UAS$b e n^{+}$;hs-Gal4 transgenic heterozygotes by heat shock-induced overexpression of ben ${ }^{+}$(Fig. 5C), indicating that the interaction between ben and Scamp is physiological rather than developmental.

We also asked whether ben and Scamp functioned together during synaptic transmission at the larval NMJ. Double labeling of larval CNS with anti-lacZ and anti-Scamp in $b e n^{P 1} / b e n^{P 1}$ flies implied that both are expressed in a similar group of motor neurons (Fig. $6 \mathrm{~A}$, arrowheads), and SCAMP immunostaining was apparent in axons of the motor neurons (Fig. $6 B$ ). The mean amplitudes of evoked EJCs at the larval NMJ in $\mathrm{ben}^{P 1} /+$ or Scamp $p^{E P} /+$ heterozygotes were similar to that in the wild-type $(+/+)$ control (Fig. 6C). In contrast, the Scamp/ Scamp homozygote or the $b e n^{P 1} /$ Scamp double heterozygote showed significantly lower EJC amplitudes, similar to that produced by the $b e n^{P 1}$ homozygote (Fig. $6 C$ ). Thus, SCAMP appears to function together with BEN during synaptic transmission at the NMJ.

\section{Discussion}

\section{Disruptions of ben impair LTM}

The ben gene resides in a genomic region, near CG5541 within the large intron of hiw (Fig. 2A). To rule out potential secondsite effects, we have shown that (1) two independently derived mutations of ben yield LTM defects when homozygous (Fig. $1 A)$; (2) a heteroallelic combination of these two mutations also disrupts LTM (Fig. 1B); (3) two independently derived mutations of hiw do not yield LTM defects when homozygous (Fig. S1 A, available at www.jneurosci.org as supplemental material); (4) heteroallelic combinations of either of these hiw mutations with $b e n^{P 1}$ do not yield LTM defects (Fig. S1B, available at www.jneurosci.org as supplemental material); (5) a heteroallelic combination of $b e n^{P 1}$ and $h i w^{N D 9}$ does not disrupt synaptic structure at the NMJ, as is the case for hiw mutants (Fig. S1C,D, available at www.jneurosci.org as supple- mental material); (6) Northern blot analyses show reduced levels of mRNA for ben, but not for hiw or CG5541, in $b e n^{P 1} / b e n^{P 1}$ or $b e n^{E Y} / b e n^{E Y}$ mutants (Fig. $2 B, C$; Fig. S2, available at www. jneurosci.org as supplemental material); (7) induced expression of a ben ${ }^{+}$transgene is sufficient to rescue the LTM defect of the $b e n^{P 1}$ mutant (Fig. $3 C, F, G$ ); and (8) induced expression of a ben ${ }^{+}$ transgene yielded an increase in ben mRNA but had no effect on hiw mRNA (Fig. $3 D, E$ ). Together, these data establish that the LTM defect of the ben mutant derives from disruption of the ben gene.

\section{Transgenic expression of ben $^{+}$in adult} MBs is sufficient to rescue the mutant

\section{LTM defect}

LTM is induced after spaced, but not massed, training (Tully et al., 1994). Massed training induces a cycloheximide-insensitive form of longlasting memory (ARM), whereas spaced training induces ARM along with a cycloheximide-sensitive LTM (Tully et al., 1994). Thus, normal $1 \mathrm{~d}$ memory after massed training suggests that learning and earlier memory is normal in ben mutants (Fig. 1 $A, B$ ), a notion also supported by normal memory 5,30 , and $180 \mathrm{~min}$ after one training session (Fig. $1 D$ ) and normal sensorimotor responses (Table 1) in the mutant. This conglomerate effect on LTM formation is not unique for ben, because disruptions of several other genes also appear specifically to impair LTM (Yin et al., 1994; Pascual and Preat, 2001; Comas et al., 2004; Ge et al., 2004; Presente et al., 2004; Didelot et al., 2006; Lu et al., 2007; Qian et al., 2007).

The LTM defect of ben can be rescued by induced expression of a $b_{e n}{ }^{+}$transgene in adults (Fig. 3C). Together with the observations that gross structural defects were not detected in the ben mutant, either in the adult brain (Figs. $3 A, 5 A$, and data not shown) or at the NMJ (Fig. S1C, available at www. jneurosci.org as supplemental material), inducible rescue indicates a physiological, rather than a developmental, role for ben during LTM formation. So where in the adult brain is ben required to function during LTM formation? Although an antibody against Ben is not yet available, we nonetheless have been able to identify neurons likely to express BEN by assessing the common expression patterns of two reporter genes in the $b^{2}{ }^{P 1}$ (LacZ) and ben $^{4013}$ (Gal4). Immunostaining for LacZ and Gal4 revealed widespread coexpression in the CNS (Fig. $3 A, B$ ) and PNS (Fig. $6 A$ ). Given that the $b e n^{\text {Galt }}$ transposon is inserted in the 5' UTR of ben, this coexpression pattern likely identifies the cells in which BEN is expressed. Although this widespread expression pattern did not provide any anatomical clues for BEN's role in LTM formation, it did suggest that BEN may be expressed in the Kenyon cells of MB.

Extensive evidence has established the MB to be involved in olfactory memory formation (Heisenberg et al., 1985; Nighorn et al., 1991; Han et al., 1992; Skoulakis et al., 1993; de Belle and Heisenberg, 1994; Connolly et al., 1996; Han et al., 1996; Grotewiel et al., 1998; Cheng et al., 2001; Philip et al., 2001; Comas et al., 2004; Didelot et al., 2006; Folkers et al., 
2006; Kim et al., 2007; Krashes et al., 2007; Lu et al., 2007; Qian et al., 2007; Xia and Tully, 2007), whereas some emerging evidence also has implicated the EB (Wu et al., 2007) (but see Krashes and Waddell, 2008). Based on these anatomical clues, we used the GAL4/ GAL $80^{\text {ts }}$ system to restrict induced expression of $b e n^{+}$to either MB or EB. The LTM defect of ben mutants was rescued with expression of a $b e n^{+}$transgene in MBs (Fig. 3F-H) but not in EBs (Fig. $3 I)$. Thus, ben may join tequila, $y u$, and chi as an LTM-specific gene with its relevant function localized to the $\mathrm{MB}$ (Didelot et al., 2006; Lu et al., 2007; Qian et al., 2007; cf. Keleman et al., 2007).

\section{BEN and SCAMP function together} during synaptic transmission at the larval NMJ

A bioinformatic search suggested that BEN and SCAMP may function together. SCAMPs are ubiquitous components of secretory vesicles in exocrine glands (Cameron et al., 1986; Brand et al., 1991; Laurie et al., 1993) and are present in recycling synaptic vesicles, where they function in clathrin-mediated vesicle budding via the asparagine-proline-phenylalamine tripeptide repeat domain (Brand et al., 1991; Brand and Castle, 1993; Hussain et al., 1999; Okamoto et al., 1999; Sengar et al., 1999; Fernandez-Chacon and Sudhof, 2000).

With this clue, we turned to the well characterized larval NMJ to assess a potential role for ben in synaptic function. We showed that BEN and SCAMP are coexpressed in some motor neurons (Fig. 6 A). Immunostaining of SCAMP was weak, however, detecting Scamp in some motor neuron terminals but not in cell bodies in the larval ganglion (Fig. 6B). Development of synaptic structure appeared normal in the $b e n^{P 1}$ mutant (Fig. S1C, available at www.jneurosci.org as supplemental material), but a defect in evoked EJC was apparent in both ben (Fig. 4B) and Scamp homozygous mutants (Fig. 6C). Importantly, evoked EJCs also were defective in ben/Scamp double heterozygotes (Fig. $6 C$ ), a classic assessment for genetic epistasis (functional interaction).

Genetic dissection of developmental plasticity at the NMJ, in fact, continues to yield results generally parallel to both behavioral plasticity in Drosophila and in mammals (Saitoe, 2001). For example, increased neural activity or cAMP signaling can produce changes in both synaptic structure and function at the NMJ (Zhong and Wu, 1991; Zhong et al., 1992). Neural excitability activates JNK (c-Jun $\mathrm{NH}_{2}$-terminal kinase) and AP-1, which then induces cAMP response elementbinding protein (CREB)-dependent changes in synaptic function (Davis et al., 1996; Sanyal et al., 2002, 2003; Etter et al., 2005) and CREB-independent, but ERK(extracellular signalregulated kinase)- and ADF1-dependent, changes in synaptic structure (Schuster et al., 1996; DeZazzo et al., 2000; Hoeffer et al., 2003). Because disruption of ben leads to defects in synaptic function rather than structure, ben appears to fall into the CREB-dependent genetic pathway for synaptic plasticity.

\section{BEN and SCAMP function together during LTM formation}

We evaluated a potential epistatic interaction between BEN and SCAMP during LTM formation. Scamp or ben heterozygotes showed normal $1 \mathrm{~d}$ memory after spaced and massed training. Ben/Scamp double heterozygotes, however, displayed a defect in $1 \mathrm{~d}$ memory after spaced training but not after massed training (Fig. 5A) or when tested immediately after a single training session (Fig. $5 B$ ). Significantly, the LTM defect of the ben/Scamp double heterozygote was rescued by induced expression of the ben ${ }^{+}$transgene (Fig. 5C), establishing that the functional interaction between ben and Scamp is physiological rather than developmental. To our knowledge, this is the first in vivo demonstration that Scamp is involved in behavioral plasticity.

\section{Normal synaptic transmission in MB may be required for} LTM formation

Our findings have established that (1) ben's function in MB is sufficient for LTM formation, (2) ben and Scamp work to- 
gether during synaptic transmission at the larval NMJ, and (3) ben and Scamp cooperate during adult LTM formation. These observations suggest the hypothesis that proper synaptic transmission in MBs may be crucial to LTM formation. Results from several other studies are consistent with this notion. MBs display persistent oscillations in neural activity in naive flies, which are disrupted in amnesiac (memory) mutants (Rosay et al., 2001). Within MBs, persistent neural activity is branch specific (Yu et al., 2005, 2006). Output from $\alpha$ lobes appears required for LTM formation (Pascual and Preat, 2001; Isabel et al., 2004). Activity within the $\alpha^{\prime} / \beta^{\prime}$ lobes is required for memory formation, whereas that in the $\alpha / \beta$ lobes is involved with retrieval (Dubnau et al., 2001; McGuire et al., 2001; Yu et al., 2006; Krashes et al., 2007; Wu et al., 2007). Our results with ben conform to this emergent view. The adult LTM defect of the ben mutant is rescued via inducible expression of a ben ${ }^{+}$transgene in either $\alpha / \beta$ lobes or $\alpha^{\prime} / \beta^{\prime}$ lobes. This implies that ben is involved in the requisite synaptic transmission underlying both memory formation and retrieval. Thus, our failure to see transgenic rescue of memory retrieval in ben mutants resides in the fact that memory formation nonetheless remained disrupted in this experiment. Our results predict that other mutations of genes, which are involved in synaptic transmission and which are expressed in MBs, also may yield (1) LTM-specific defects and (2) MBsufficient rescue thereof. Perhaps this cellular dysfunction (abnormal neural activity) is the unifying phenotype underlying all olfactory memory genes with critical function localized to the MB.

\section{References}

Akalal DB, Wilson CF, Zong L, Tanaka NK, Ito K, Davis RL (2006) Roles for Drosophila mushroom body neurons in olfactory learning and memory. Learn Mem 13:659-668.

Ashraf SI, McLoon AL, Sclarsic SM, Kunes S (2006) Synaptic protein synthesis associated with memory is regulated by the RISC pathway in Drosophila. Cell 124:191-205.

Bellen HJ, Levis RW, Liao G, He Y, Carlson JW, Tsang G, Evans-Holm M, Hiesinger PR, Schulze KL, Rubin GM, Hoskins RA, Spradling AC (2004) The BDGP gene disruption project: single transposon insertions associated with 40\% of Drosophila genes. Genetics 167:761-781.

Bolduc F, Bell K, Cox H, Broadie K, Tully T (2008) Excess protein synthesis in Drosophila Fragile X mutants impairs long-term memory. Nat Neurosci 11:1143-1145.

Brand SH, Castle JD (1993) SCAMP 37, a new marker within the general cell surface recycling system. EMBO J 12:3753-3761.

Brand SH, Laurie SM, Mixon MB, Castle JD (1991) Secretory carrier membrane proteins 31-35 define a common protein composition among secretory carrier membranes. J Biol Chem 266:18949-18957.

Cameron RS, Cameron PL, Castle JD (1986) A common spectrum of polypeptides occurs in secretion granule membranes of different exocrine glands. J Cell Biol 103:1299-1313.

Cheng Y, Endo K, Wu K, Rodan AR, Heberlein U, Davis RL (2001) Drosophila fasciclinII is required for the formation of odor memories and for normal sensitivity to alcohol. Cell 105:757-768.

Chiang AS, Liu YC, Chiu SL, Hu SH, Huang CY, Hsieh CH (2001) Threedimensional mapping of brain neuropils in the cockroach, Diploptera punctata. J Comp Neurol 440:1-11.

Chiang AS, Lin WY, Liu HP, Pszczolkowski MA, Fu TF, Chiu SL, Holbrook GL (2002) Insect NMDA receptors mediate juvenile hormone biosynthesis. Proc Natl Acad Sci U S A 99:37-42.

Comas D, Petit F, Preat T (2004) Drosophila long-term memory formation involves regulation of cathepsin activity. Nature 430:460-463.

Connolly JB, Roberts IJ, Armstrong JD, Kaiser K, Forte M, Tully T, O’Kane CJ
(1996) Associative learning disrupted by impaired Gs signaling in Drosophila mushroom bodies. Science 274:2104-2107.

Davis GW, Schuster CM, Goodman CS (1996) Genetic dissection of structural and functional components of synaptic plasticity. III. CREB is necessary for presynaptic functional plasticity. Neuron 17:669-679.

de Belle JS, Heisenberg M (1994) Associative odor learning in Drosophila abolished by chemical ablation of mushroom bodies. Science 263:692-695.

DeZazzo J, Sandstrom D, de Belle S, Velinzon K, Smith P, Grady L, DelVecchio M, Ramaswami M, Tully T (2000) nalyot, a mutation of the Drosophila myb-related Adf1 transcription factor, disrupts synapse formation and olfactory memory. Neuron 27:145-158.

Didelot G, Molinari F, Tchenio P, Comas D, Milhiet E, Munnich A, Colleaux L, Preat T (2006) Tequila, a neurotrypsin ortholog, regulates long-term memory formation in Drosophila. Science 313:851-853.

Dubnau J, Grady L, Kitamoto T, Tully T (2001) Disruption of neurotransmission in Drosophila mushroom body blocks retrieval but not acquisition of memory. Nature 411:476-480.

Dubnau J, Chiang AS, Grady L, Barditch J, Gossweiler S, McNeil J, Smith P, Buldoc F, Scott R, Certa U, Broger C, Tully T (2003) The staufen/pumilio pathway is involved in Drosophila long-term memory. Curr Biol 13:286-296.

Etter PD, Narayanan R, Navratilova Z, Patel C, Bohmann D, Jasper H, Ramaswami M (2005) Synaptic and genomic responses to JNK and AP-1 signaling in Drosophila neurons. BMC Neurosci 6:39.

Fernandez-Chacon R, Sudhof TC (2000) Novel SCAMPs lacking NPF repeats: ubiquitous and synaptic vesicle-specific forms implicate SCAMPs in multiple membrane-trafficking functions. J Neurosci 20:7941-7950

Folkers E, Waddell S, Quinn WG (2006) The Drosophila radish gene encodes a protein required for anesthesia-resistant memory. Proc Natl Acad Sci U S A 103:17496-17500.

Ge X, Hannan F, Xie Z, Feng C, Tully T, Zhou H, Xie Z, Zhong Y (2004) Notch signaling in Drosophila long-term memory formation. Proc Natl Acad Sci U S A 101:10172-10176.

Giot L, Bader JS, Brouwer C, Chaudhuri A, Kuang B, Li Y, Hao YL, Ooi CE, Godwin B, Vitols E, Vijayadamodar G, Pochart P, Machineni H, Welsh M, Kong Y, Zerhusen B, Malcolm R, Varrone Z, Collis A, Minto M, et al. (2003) A protein interaction map of Drosophila melanogaster. Science 302:1727-1736.

Grotewiel MS, Beck CD, Wu KH, Zhu XR, Davis RL (1998) Integrinmediated short-term memory in Drosophila. Nature 391:455-460.

Han PL, Levin LR, Reed RR, Davis RL (1992) Preferential expression of the Drosophila rutabaga gene in mushroom bodies, neural centers for learning in insects. Neuron 9:619-627.

Han PL, Meller V, Davis RL (1996) The Drosophila brain revisited by enhancer detection. J Neurobiol 31:88-102.

Heisenberg M, Borst A, Wagner S, Byers D (1985) Drosophila mushroom body mutants are deficient in olfactory learning. J Neurogenet $2: 1-30$.

Hoeffer CA, Sanyal S, Ramaswami M (2003) Acute induction of conserved synaptic signaling pathways in Drosophila melanogaster. J Neurosci 23:6362-6372.

Hubbard C, Singleton D, Rauch M, Jayasinghe S, Cafiso D, Castle D (2000) The secretory carrier membrane protein family: structure and membrane topology. Mol Biol Cell 11:2933-2947.

Hussain I, Bate GW, Henry J, Djali P, Dimaline R, Dockray GJ, Varro A (1999) Modulation of gastrin processing by vesicular monoamine transporter type 1 (VMAT1) in rat gastrin cells. J Physiol 517:495-505.

Isabel G, Pascual A, Preat T (2004) Exclusive consolidated memory phases in Drosophila. Science 304:1024-1027.

Jan LY, Jan YN (1976) Properties of the larval neuromuscular junction in Drosophila melanogaster. J Physiol 262:189-214. 
Keene AC, Waddell S (2007) Drosophila olfactory memory: single genes to complex neural circuits. Nat Rev Neurosci 8:341-354.

Keleman K, Kruttner S, Alenius M, Dickson BJ (2007) Function of the Drosophila CPEB protein Orb2 in long-term courtship memory. Nat Neurosci 10:1587-1593.

Kim YC, Lee HG, Han KA (2007) D1 dopamine receptor dDA1 is required in the mushroom body neurons for aversive and appetitive learning in Drosophila. J Neurosci 27:7640-7647.

Krashes MJ, Waddell S (2008) Rapid consolidation to a radish and protein synthesis-dependent long-term memory after single-session appetitive olfactory conditioning in Drosophila. J Neurosci 28:3103-3113.

Krashes MJ, Keene AC, Leung B, Armstrong JD, Waddell S (2007) Sequential use of mushroom body neuron subsets during Drosophila odor memory processing. Neuron 53:103-115.

Landmesser LT (1998) Synaptic plasticity: keeping synapses under control. Curr Biol 8:R564-R567.

Laurie SM, Cain CC, Lienhard GE, Castle JD (1993) The glucose transporter GluT4 and secretory carrier membrane proteins (SCAMPs) colocalize in rat adipocytes and partially segregate during insulin stimulation. J Biol Chem 268:19110-19117.

Littleton JT (2000) A genomic analysis of membrane trafficking and neurotransmitter release in Drosophila. J Cell Biol 150:F77-F82.

Lloyd TE, Verstreken P, Ostrin EJ, Phillippi A, Lichtarge O, Bellen HJ (2000) A genome-wide search for synaptic vesicle cycle proteins in Drosophila. Neuron 26:45-50.

Lu Y, Lu YS, Shuai Y, Feng C, Tully T, Xie Z, Zhong Y, Zhou HM (2007) The AKAP Yu is required for olfactory long-term memory formation in Drosophila. Proc Natl Acad Sci U S A 104:13792-13797.

Margulies C, Tully T, Dubnau J (2005) Deconstructing memory in Drosophila. Curr Biol 15:R700-R713.

McGuire SE, Le PT, Davis RL (2001) The role of Drosophila mushroom body signaling in olfactory memory. Science 293:1330-1333.

McGuire SE, Le PT, Osborn AJ, Matsumoto K, Davis RL (2003) Spatiotemporal rescue of memory dysfunction in Drosophila. Science 302:1765-1768.

Nighorn A, Healy MJ, Davis RL (1991) The cyclic AMP phosphodiesterase encoded by the Drosophila dunce gene is concentrated in the mushroom body neuropil. Neuron 6:455-467.

O'Connell PO, Rosbash M (1984) Sequence, structure, and codon preference of the Drosophila ribosomal protein 49 gene. Nucleic Acids Res 12:5495-5513.

Okamoto PM, Tripet B, Litowski J, Hodges RS, Vallee RB (1999) Multiple distinct coiled-coils are involved in dynamin self-assembly. J Biol Chem 274:10277-10286.

Pascual A, Preat T (2001) Localization of long-term memory within the Drosophila mushroom body. Science 294:1115-1117.

Petersen SA, Fetter RD, Noordermeer JN, Goodman CS, DiAntonio A (1997) Genetic analysis of glutamate receptors in Drosophila reveals a retrograde signal regulating presynaptic transmitter release. Neuron 19:1237-1248.

Philip N, Acevedo SF, Skoulakis EM (2001) Conditional rescue of olfactory learning and memory defects in mutants of the 14-3-3zeta gene leonardo. J Neurosci 21:8417-8425.

Presente A, Boyles RS, Serway CN, de Belle JS, Andres AJ (2004) Notch is required for long-term memory in Drosophila. Proc Natl Acad Sci U S A 101:1764-1768.

Qian M, Pan G, Sun L, Feng C, Xie Z, Tully T, Zhong Y (2007) Receptor-like tyrosine phosphatase PTP10D is required for long-term memory in Drosophila. J Neurosci 27:4396-4402.

Riemensperger T, Voller T, Stock P, Buchner E, Fiala A (2005) Punishment prediction by dopaminergic neurons in Drosophila. Curr Biol 15:1953-1960.

Rosay P, Armstrong JD, Wang Z, Kaiser K (2001) Synchronized neural ac- tivity in the Drosophila memory centers and its modulation by amnesiac. Neuron 30:759-770.

Saitoe MT, Tully T (2001) Making connections between developmental and behavioral plasticity in Drosophila. In: Toward a theory of neuroplasticity (Shaw CA, McEachern JC, eds), pp 193-220. New York: Psychology Press.

Sanyal S, Sandstrom DJ, Hoeffer CA, Ramaswami M (2002) AP-1 functions upstream of CREB to control synaptic plasticity in Drosophila. Nature 416:870-874.

Sanyal S, Narayanan R, Consoulas C, Ramaswami M (2003) Evidence for cell autonomous AP1 function in regulation of Drosophila motor-neuron plasticity. BMC Neurosci 4:20.

Schuster CM, Davis GW, Fetter RD, Goodman CS (1996) Genetic dissection of structural and functional components of synaptic plasticity. II. Fasciclin II controls presynaptic structural plasticity. Neuron 17:655-667.

Schwaerzel M, Heisenberg M, Zars T (2002) Extinction antagonizes olfactory memory at the subcellular level. Neuron 35:951-960.

Schwaerzel M, Monastirioti M, Scholz H, Friggi-Grelin F, Birman S, Heisenberg M (2003) Dopamine and octopamine differentiate between aversive and appetitive olfactory memories in Drosophila. J Neurosci 23:10495-10502.

Sengar AS, Wang W, Bishay J, Cohen S, Egan SE (1999) The EH and SH3 domain Ese proteins regulate endocytosis by linking to dynamin and Eps15. EMBO J 18:1159-1171.

Singh S, Wu CF (1989) Complete separation of four potassium currents in Drosophila. Neuron 2:1325-1329.

Skoulakis EM, Kalderon D, Davis RL (1993) Preferential expression in mushroom bodies of the catalytic subunit of protein kinase A and its role in learning and memory. Neuron 11:197-208.

Stark C, Breitkreutz BJ, Reguly T, Boucher L, Breitkreutz A, Tyers M (2006) BioGRID: a general repository for interaction datasets. Nucleic Acids Res 34:D535-D539.

Stewart BA, Atwood HL, Renger JJ, Wang J, Wu CF (1994) Improved stability of Drosophila larval neuromuscular preparations in haemolymphlike physiological solutions. J Comp Physiol A Neuroethol Sens Neural Behav Physiol 175:179-191.

Tully T, Quinn WG (1985) Classical conditioning and retention in normal and mutant Drosophila melanogaster. J Comp Physiol A Neuroethol Sens Neural Behav Physiol 157:263-277.

Tully T, Preat T, Boynton SC, Del Vecchio M (1994) Genetic dissection of consolidated memory in Drosophila. Cell 79:35-47.

Tully T, Bolwig G, Christensen J, Connolly J, DeZazzo J, Dubnau J, Jones C, Pinto S, Regulski M, Svedberg F, Velinzon K (1996) Genetic dissection of memory in Drosophila. J Physiol (Paris) 90:383.

Waddell S, Armstrong JD, Kitamoto T, Kaiser K, Quinn WG (2000) The amnesiac gene product is expressed in two neurons in the Drosophila brain that are critical for memory. Cell 103:805-813.

Wan HI, DiAntonio A, Fetter RD, Bergstrom K, Strauss R, Goodman CS (2000) Highwire regulates synaptic growth in Drosophila. Neuron 26:313-329.

Wang Y, Mamiya A, Chiang AS, Zhong Y (2008) Imaging of an early memory trace in the Drosophila mushroom body. J Neurosci 28:4368-4376.

Wu C, Wairkar YP, Collins CA, DiAntonio A (2005) Highwire function at the Drosophila neuromuscular junction: spatial, structural, and temporal requirements. J Neurosci 25:9557-9566.

Wu CF, Haugland FN (1985) Voltage clamp analysis of membrane currents in larval muscle fibers of Drosophila: alteration of potassium currents in Shaker mutants. J Neurosci 5:2626-2640.

Wu C-L, Xia S, Fu T-F, Wang H, Chen Y-H, Leong D, Chiang AS, Tully T (2007) Specific requirement of NMDA receptors for long-term memory consolidation in Drosophila ellipsoid body. Nat Neurosci 10:1578-1586

Wu Y, Bolduc FV, Bell K, Tully T, Fang Y, Sehgal A, Fischer JA (2008) A 
Drosophila model for Angelman syndrome. Proc Natl Acad Sci U S A 105:12399-12404.

Xia S, Tully T (2007) Segregation of odor identity and intensity during odor discrimination in Drosophila mushroom body. PLoS Biol 5:e264.

Xia S, Miyashita T, Fu TF, Lin WY, Wu CL, Pyzocha L, Lin IR, Saitoe M, Tully $\mathrm{T}$, Chiang AS (2005) NMDA receptors mediate olfactory learning and memory in Drosophila. Curr Biol 15:603-615.

Yin JC, Wallach JS, Del Vecchio M, Wilder EL, Zhou H, Quinn WG, Tully T (1994) Induction of a dominant negative CREB transgene specifically blocks long-term memory in Drosophila. Cell 79:49-58.

Yu D, Ponomarev A, Davis RL (2004) Altered representation of the spatial code for odors after olfactory classical conditioning; memory trace formation by synaptic recruitment. Neuron 42:437-449.
Yu D, Keene AC, Srivatsan A, Waddell S, Davis RL (2005) Drosophila DPM neurons form a delayed and branch-specific memory trace after olfactory classical conditioning. Cell 123:945-957.

Yu D, Akalal DB, Davis RL (2006) Drosophila alpha/beta mushroom body neurons form a branch-specific, long-term cellular memory trace after spaced olfactory conditioning. Neuron 52:845-855.

Zars T, Fischer M, Schulz R, Heisenberg M (2000) Localization of a shortterm memory in Drosophila. Science 288:672-675.

Zhong Y, Wu CF (1991) Altered synaptic plasticity in Drosophila memory mutants with a defective cyclic AMP cascade. Science 251:198-201.

Zhong Y, Budnik V, Wu CF (1992) Synaptic plasticity in Drosophila memory and hyperexcitable mutants: role of cAMP cascade. J Neurosci 12: 644-651. 